\title{
Estudo laparoscópico dos órgãos abdominais do eqüino por abordagem mediana ventral
}

\section{Laparoscopic study of horse abdominal viscera by ventral midline approach}

\author{
Iuís Cláudio Lopes Correia da SILVA'; Waldir GANDOI,FI²; José de ALVARENGA'; \\ Denise 'Tabachi FANTONI'
}

Correspondence to:
Luís Cláudio Lopes Correia da
Silva
Departamento de Cirurgia
Faculdade de Medicina
Veterinária e Zootecnia da USP
Av. Prof. Dr. Orlando Marques
de Paiva, 87 - Cidade
Universitária Armando Salles de
Oliveira
CEP 05508-900 São Paulo - SP
- Brasil
e-mail: dfantoni@usp.br
1. Departamento de Cirurgia
Faculdade de Medicina
Veterinária e Zootecnia
da USP - SP
2. Departamento de Cirurgia
Faculdade de Medicina
Veterinária e Zootecnia da
UNESP, Botucatu, SP

\section{RESUMO}

O presente trabalho descreve a disposição topográfica das vísceras abdominais do eqüino por via laparoscópica, com abordagem mediana ventral, em 3 diferentes vias de acesso: retroxifóide, pré-umbilical e retro-umbilical. Foram realizados 51 exames laparoscópicos, utilizando-se 17 eqüinos, sendo 11 machos e 6 fêmeas, de diferentes raças e idade variando de 18 meses a 24 anos, submetidos a jejum alimentar de 36 horas e hidrico de 12 horas. Os animais foram sedados com acepromazina e para indução à anestesia foram utilizados éter gliceril guaiacólico, midazolan e cloridrato de quetamina. A manutenção da anestesia foi feita por via inalatória com halotano. Durante o procedimento os animais foram mantidos em decúbito dorsal. Com intuito de melhor observação dos órgãos instaurou-se pneumoperitônio com ar ambiente. Tal abordagem permitiu a observaçāo da cúpula diafragmática, centro frênico, estômago, epíploon, lobos hepáticos, baço, ceco, vários segmentos do cólon maior, cólon menor e intestino delgado, bexiga, útero e anéis ingüinais. Não ocorreram complicaçōes durante os periodos pré, trans e pós-operatórios, demonstrando ser um método seguro de avaliação da cavidade peritoneal, vindo a ser complementar às abordagens já descritas na literatura para laparoscopia diagnóstica em eqüinos.

\section{UNITERM()S: Laparoscopia; Endoscopia; Peritoneoscopia; Equidae}

\section{INTRODUÇÃO}

$\mathrm{E}$ m Medicina Veterinária, as técnicas de diagnóstico por imagem mais difundidas são a radiografia, a ultrasonografia e a endoscopia. Estas três lécnicas isoladamente ou associadas propiciam importante ferramenta ao clínico veterinário. A laparoscopia, também chamada de peritonioscopia, ¿ técnica invasiva que permite a visualização direta da cavidade abdominal e da superficie peritoneal com o uso de um laparoscópio ${ }^{10}$. Tal procedimento causa traumatismo mínimo à parede abdominal se comparado à laparotomia exploratória, além da não exposição direta da cavidade ao meio externo. Esta téenica tem sido largamente utilizada em medicina humana como método diagnóstico e terapêutico.

A aplicação da laparoscopia em Medicina Veterinária visou inicialmente apenas a realização de estudos dos órgãos reprodutivos internos em femeas de várias especies animais $2,11,12,14.15,17.18 .19,20,23,26$. Seu emprego clínico visa a inspeçào dos órgãos abdominais c a avaliação de possíveis processos patológicos 4.7.9.10\%.25, além da orientação visual para coleta de material através de biópsia e aspirado para exame histopatológico e citológico respectivamente 5.7 .9 .25 . Mais recentemente, a laparoscopia tem sido utilizada também em intervençòes cirúrgicas, denominadas de cirurgias laparoscópicas, como por exemplo a castração em cães e gatos ${ }^{16,22.23}$, e a retirada de testículo criptorquidico e ovário em eqüino ${ }^{3.5}$

Em animais de pequeno e médio porte, o posicionamento para a realização do exarne deve $\mathrm{ser} \mathrm{em}$ decúbito $2,6,7,9.10,16,20,21.22 .23 .24$, enquanto que em animais adultos de espécies de grande porte utiliza-se principalmente o posicionamento quadrupedal, evitando-se assim a realização de anestesia geral no paciente. Alguns autores têm utilizado o decúbito para exploraçiōo laparoscópica em grandes animais 1.3 .8

Para melhor visualização das estruturas anatômicas abdominais emprega-se a técnica de pneumoperitónio, a qual promove um afastamento da parede abdominal em relação aos órgãos intra-cavitários. Os gases empregados podem ser dióxido de carbono $^{8.17 .23 .26}$, oxido nitroso $0^{25}$, oxigênio $0^{6.8}$, e ar ambiente 2.8 .11 , além da mistura de dois destes gases ${ }^{20.21}$. O uso de pinça de preensão de órgãos é auxiliar na exploração laparoscópica 2.6,7.10.

Descrições da anatomia topográfica laparoscópica $\mathrm{cm}$ eqüinos são encontradas na literatura apenas através de abordagem lateral, realizando o acesso pelos flancos direito e esquerdo, com o animal posicionado em estação ${ }^{4,19,25}$.

Com a finalidade de estudar os órgãos reprodutivos internos da égua por via laparoscópica, Wilson ${ }^{25}(1983)$ empregou o acesso pelo flanco esquerdo. Para distender o abdomen utilizou insuflador automático de óxido nitroso. O pneumoperitônio foi instituido com 
fluxo de gás de llitro / min, ate um limite máximo de $40 \mathrm{mml}$ lg. e posteriormente mantido constante, não excedendo $20 \mathrm{~mm} / \mathrm{g}$. No estudo realizado os animais foram sedados com cloridrato de xilazina, seguido de administração intravenosa de morfina c anestesiados localmente com lidocaína.

() uso clínico de laparoscopia em eqüinos foi demonstrado por Fischer $\%$ al. ${ }^{4}(1986)$ com o relato de cinco casos clínicos de aplicação da técnica com o paciente em posição quadrupedal e abordagem pelo flanco. Diagnosticaram-se um hematoma em mesocólon, dois abscessos abdominais, sendo um com extensas aderências intestinais, um carcinoma gástrico e um teratoma ovariano. () jejum preconizado pelos autores é de 24 a 36 horas antes do exame para minimizar a distensão intestinal, principalmente com gases. A sedação e analgesia é realizada com associação de cloridrato de xilazina e butorfanol.

O presente estudo tem por objetivo oferecer nova opção de abordagem laparoscópica em eqüinos. Com esta finalidade optouse pela realização de três pontos de acesso à cavidade abdominal pela linha mediana ventral. $\wedge$ partir destes acessos descreveremos a distribuiçào topográfica das vísceras abdominais do eqüino posicionado em decúbito dorsal.

\section{MATERIAL E MÉTODO}

\section{EQUIPAMENTO}

O equipamento utilizado para a realização deste experimento constituiu-se dos seguintes elementos:

1. L aparoscópio de visão frontal, com $11 \mathrm{~mm}$ de diâmetro c $31 \mathrm{~cm}$ de comprimento, com canal interno de passagem de pinça (1) (Fig.l).

2. Fonte de luz com 2 saidas e lâmpadas de 150 watts (2).

3. (abo flexivel de fibra óptica com $2.0 \mathrm{~m}$ de comprimento (2).

4. Conjunto trocarte-cânula $\mathrm{com} 12 \mathrm{~mm}$ de diâmetro $\mathrm{c} 16 \mathrm{~cm}$ de comprimento, de ponta cônica c válvula de segurança por esfera de aço imantada para evitar a perda de ar intra-abdominal (1) (Fig.1). 5. Conjunto trocarte-cânula para passagem de pinça de preensão, com $7 \mathrm{~mm}$ de diâmetro, $18 \mathrm{~cm}$ de comprimento e dotado de válvula de segurança (8) (Fig. 1).

6. Pinça de preensão de órgãos com $50 \mathrm{~cm}$ de comprimento (1) (Fig. l).

7. Agulha de Verres de $12 \mathrm{~cm}$ de comprimento e calibre de $2 \mathrm{~mm}$, com ponta romba retrátil através de sistema interno de mola, expondo o bizel da agulhá apenas quando submetida a pressão (1) (Fig. I).

8. Compressor de ar para instauração do pneumoperitônio (4).

\section{PROCEDIMENTO}

Foram utilizados 17 eqüinos, de ambos os sexos, sendo 11 machos e 6 fêmeas, de diferentes raças, com idade variando

\footnotetext{
- (1) - VEB MLW Medizinische Geräte Berlin

- (2) - Reichenbach.

- (3) - Karl Storz.

- (4) - K. Takaoka, modelo 13000.
}

entre 18 meses e 24 anos, e peso corpóreo de 170 a $420 \mathrm{Kg}$.

Após jejum alimentar de 36 horas e hídrico de 12 horas. os animais foram submetidos a sedação com acepromazina(1) na dose de $0,1 \mathrm{mg} / \mathrm{Kg}$ de peso corpóreo, por via intravenosa. Decorridos 15 minutos, aplicou-se por via intravenosa associação de midazolam(2) na dose de 0, $15 \mathrm{mg}$ / Kgecéter gliceril guaiacólico(3) na dose de $100 \mathrm{mg} / \mathrm{Kg}$, ambos diluidos $\mathrm{cm} 500 \mathrm{ml}$ de solução glicosada a $5 \%$, o que prontamente levou o animal ao decubito lateral. A indução anestésica foi obtida com aplicação de cloridrato de quetamina (4) na dose de 1 ,0 mg Kg. por via intravenosa. Seguiuse a intubação orotraqueal, transporte do animal da sala de inclução ao centro cirúrgico, e manutenção anestésica com halotano(5) vaporizado $\mathrm{cm}$ oxigênio por aparelho de anestesia inalatória para grandes animais(6). Uma vez atingido plano anestésico satisfatório. o animal foi posicionado em decúbito dorsal.

Manteve-se monitorização no período trans-operatorio através de monitor cardíaco(7) e medição constante da pressão arterial média por técnica invasiva.

Com o paciente posicionado $\mathrm{cm}$ decúbito dorsal realizou-scampla depilação da região ventral do abdómen, limpeza da pele e aplicação tópica de solução de iodopovidona a 1\% (8). Após 10 minutos procedeu-se a anti-sepsia com álcool 70\%. seguida de montagem do campo operatório com panos esterilizados.

Todo o material de laparoscopia foi esterilizado por imersão em solução de glutaraldeido a $2 \%$ (9) durante 40 minutos e posteriormente enxaguado com solução de cloreto de sódio a $0.9 \%$ para retirada do excesso, evitando desta forma a irritação dos tecidos moles e principalmente do peritônio pelo glutaraldeído.

$\Lambda$ pós prática de pequena incisão de pele introduziu-se a agulha de Verres pela cicatriz umbilical em direção dorsocranial até posicioná-la na cavidade peritoneal (Fig. 2). Iniciou-se a insuflaçào da cavidade com ar ambiente, mantendo-se atençâo para que não houvesse distensão irregular da parede, o que poderia significar punção intestinal ou retroperitoneal. Tambèm durante este periodo. que durou em média de 3 a 5 minutos, dependendo do porte do animal, observou-se quanto a possíveis alteraçòes da função cardiorrespiratória do paciente. $\Lambda$ pressão intra-abdominal foi mantida em aproximadamente 15 a $20 \mathrm{mmlg}$, chegando ao máximo de $25 \mathrm{mmltg}$ o que permitiu distensão apropriada da. parede abdominal, a qual foi controlada por percussão digital do abdômen.

Foram utilizados três acessos para introdução do trocartecânula. mantendo-se a seguinte seqüência:

- Acesso retroxifóde - RX: abordando a região cranial ou anterior do abdômen, com ponto de inserção situado na linha alba. aproximadamente $10 \mathrm{~cm}$ caudal ao processo xifóide (Fig. 2).

- Acesso pré-umbilical - PU: abordando a região central, com inserção do trocarte na linha alba, $15 \mathrm{~cm}$ cranial a cicatriz umbilical (Fig. 2).

- Acesso retro-umbilical - RU: abordando a região caudal ou

(1) Acepran 1\% - Univet S.A. - Industria Veterinaria

(2) Dormonid - Produtos Roche Quimicos e Farmacêuticos S.A.

(3) Eter gliceril guaiacólico - Henrifarma S.A.

(4) Vetanarcol-Laboratórios König S.A. - Argentina

(5) Halotano Hoescht - Hoescht AG - Alemanha

(5) Mallard Medical - modelo 2800 LAAV

(2) Dixtal, modelo $0 \times 2710$

Povidine - Johnson Llda - Divisão Hospitalar

Glutatec - Tecnofarma Indústria e Comércio Lida 


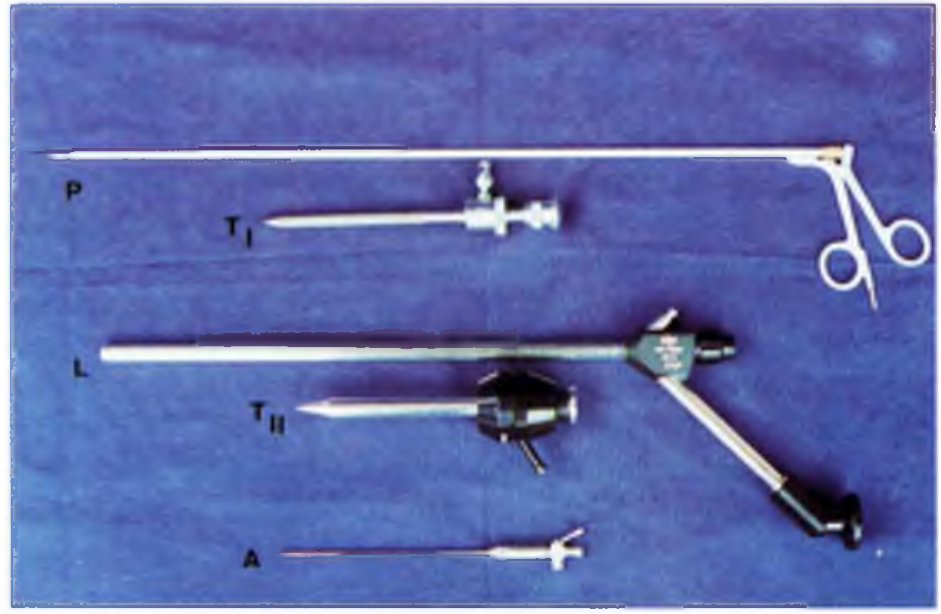

Figura 1

Material utilizado para laparoscopia. P: pinça de preensão, T I : conjunto trocarte-cânula para pinça, T II : trocarte-cânula para laparoscópio, L: laparoscópio, A: agulha de Verres.

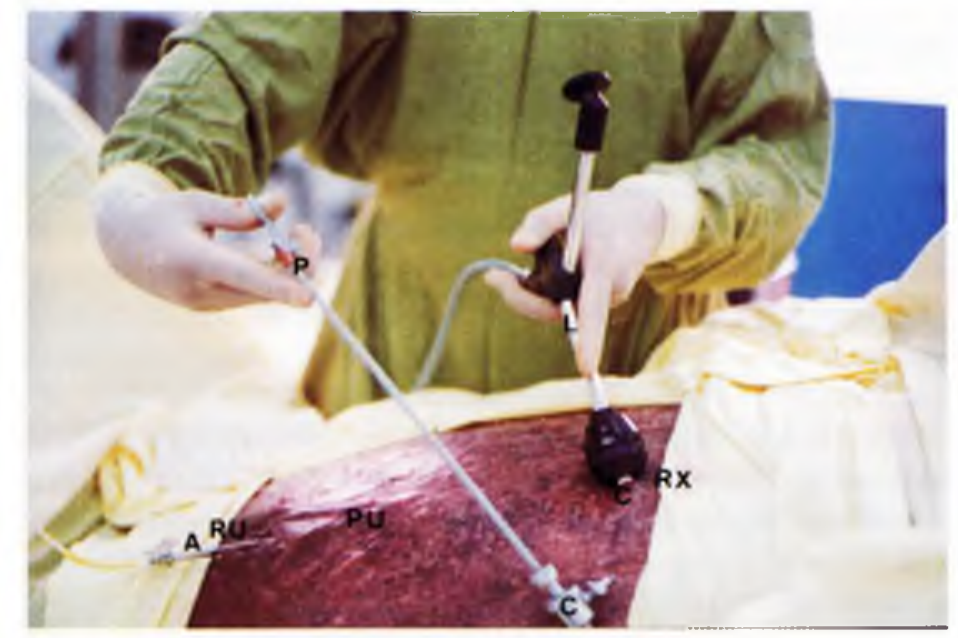

Figura 2

Início da exploração da cavidade abdominal pelo acesso rełro-xifóide. RX: retro-xifóide, PU: pré-umbilical, RU: retro-umbilical, L: laparoscópio, $C$ : cânulas, P: pinça de preensão, A: agulha de Verres.

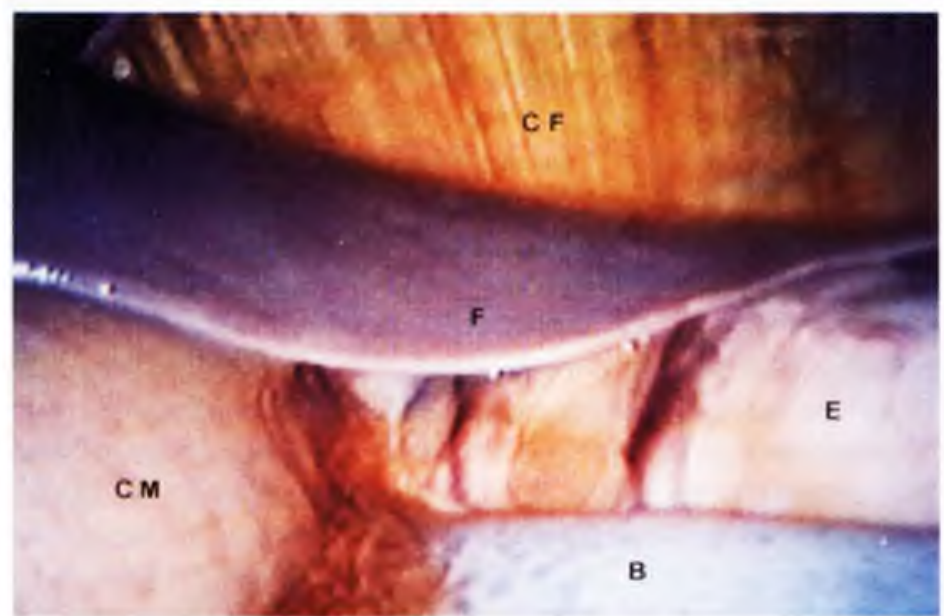

Figura 3

Fotografia de visão laparoscópica da região cranial esquerda do abdômen eqüino. F: fígado, B: baço, E: estômago, CM: cólon maior, CF: centro frênico.

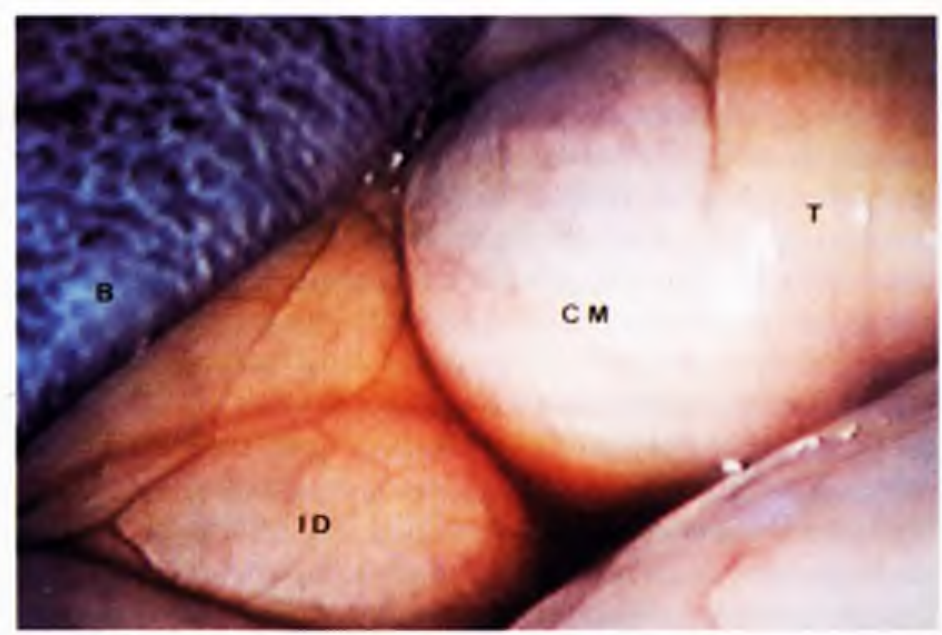

Figura 4

Fotografia de visão laparoscópica da região central esquerda do abdômen eqüino. B: baço, $\mathrm{CM}$ : cólon menor, $\mathrm{T}$ : tênia antimesentérica do cólon menor, ID: intestino delgado recoberto pelo seu mesentério.

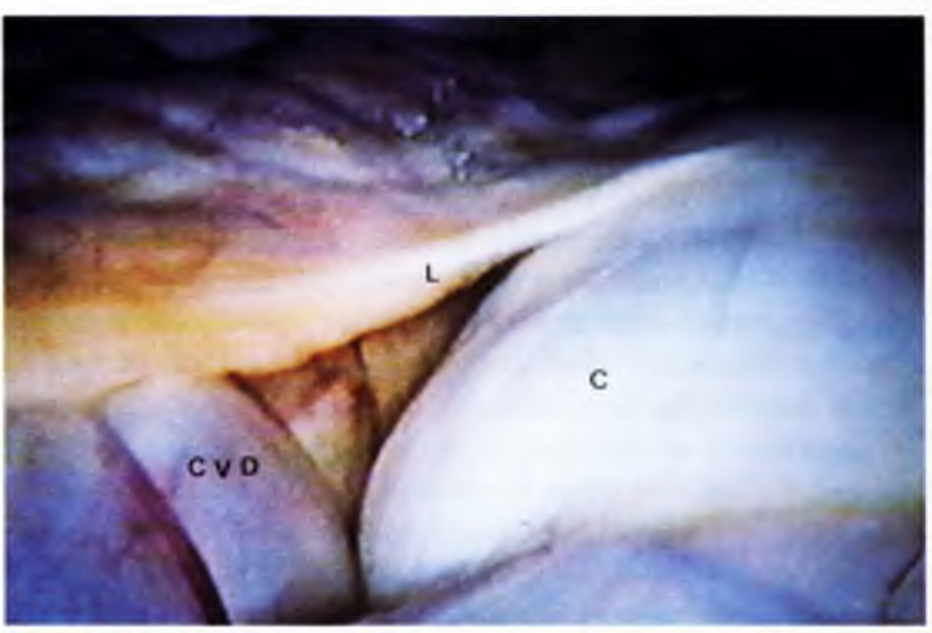

Figura 5

Fołografia de visão laparoscópica da região central direiła do abdômen eqüino. C: corpo do ceco, CVD: cólon ventral direito, L: ligamento cecocólico.

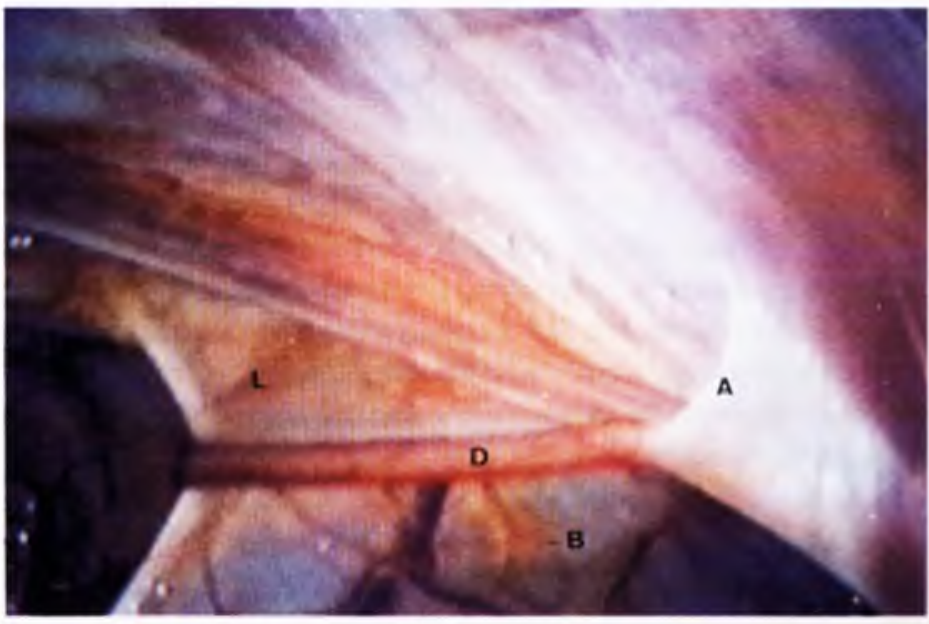

Figura 6

Fotografia de visão laparoscópica da região caudal esquerda do abdômen eqüino. $\mathrm{D}$ : ducto deferente, $\mathrm{A}$ : anel inguinal, L: ligamento lateral da bexiga, B: bexiga recoberta pelo seu ligamento. 


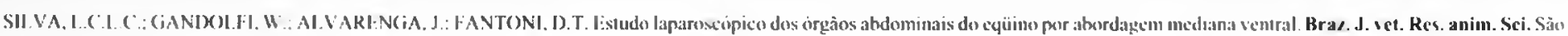
Paule, v.14. 8.4, P.211-217. 1997

posicrior do abdomen, com introduçào do trocarte pela linha alba, $5 \mathrm{~cm}$ caudal à cicatriz umbilical (Fig. 2).

A perfuração da parede abdominal pelo trocarte, após incisão de pele de aproximadamente $1,5 \mathrm{~cm}$, foi realizada por divulsão romba através da extremidade connica do trocarte. direcionado dorsocranialmente, com pressão manual constante associada a movimentos rotatórios semicirculares do conjunto. () trocarte loi entào retirado, mantendo-se a cânula fixa, pronta para receber o laparoscópio.

Com o intuito de auxiliar a inspeção dos órgãos, optou-se pela introdução de um segundo conjunto trocarte-cânula, lateralmente a direita ou à esquerda do laparoscopio, distando aproximadamente 20 a $30 \mathrm{~cm}$ da linha média (Fig. 2). Por esta segunda cânula fixada pôde-se introduzir a pinça de preensão, a qual permitia a fastamento ou tração de estruturas leves, facilitando c ampliando a capacidade de visualização.

Foram levados em consideração durante a observação: a identificaçào do órgào ou estrutura, qual o segmento visualizado. a regiào ocupada e sua relação com outros componentes adjacentes.

listes dados obtidos foram distribuidos segundo a região abordada:

- Regiào cranial - (ontida no espaço delimitado cranialmente pela cupula diafragmática e caudalmente pelo ponto médio entre as vias de acesso retroxifóide e pré-umbilical.

- Região central - Compreendida entre o limite caudal da regiào cranial e o ponto médio entre os acessos pré e retro-umbilical.

- Regiào caudal - Compreendida entre o limite caudal da região central e a pelve.

Ao término da exploraçào laparoscópica pelo terceiro e último acesso, o laparoscópio c a cânula foram retirados da cavidade, permitindo a drenagem lenta do ar intra-abdominal através dos lábios da ferida. () ar residual era retirado pela compressão da parede abdominal, acompanhada de afastamento das bordas com pinça hemostatica. Neste momento retiraval-se a agulha de Verres.

Finalmente, todas as incisoes de pele cram suturadas em pontos simples separados com fio de m/on monofilamentado $n^{\circ}$ ) (1). Ao término do procedimento cirurgico o animal foi transportado à baia de recuperação, onde foi extubado após iniciar reflexo de deglutiçào.

Optou-se pela nào-administraçào de analgésicos e antibióticos com base no discreto tramatismo causado pelo método, além do baixo risco de contaminação da cavidade peritoncal $\mathrm{cm}$ consegüência dos cuidados de assepsia e anti-sepsia empregados.

Uma vez em posiçào quadrupedal, apresentando boa locomoção, os animais foram mantidos em baias individuais. A alimentação consistiu de feno e água no primeiro dia. passando nos dias subseqüentes a ser suplementada com raçio própria para cqüinos. Observaçòes diárias. por um período mínimo de 21 dias, foram realizadas objetivando avaliação do estado geral, com especial atenção à demonstraçào de dor, apetite, delecaçào e micção.

\section{RESULTADOS}

() jejum alimentar de 36 horas e hidrico de 12 horas foi suficiente para se obter esvaziamento parcial dos vários (1) Superion O - Cirumédica S.A. compartimentos intestinais, possibilitando desta forma boa visualizaçào das diversas estruturas anatomicas. A associaçào de drogas anestésicas empregadas neste experimento conferiu boa qualidade à anestesia. Indução, manutenção e recuperação anestésicas transcorreram de forma trancüila e segura.

A utilização de soluçào de iodopovidona a $1 \%$ seguido de álcool 70\% para a anti-sepsia do campo operatório e solução de glutaraldeido a $2 \%$ como método de desinfeccão do equipamento mostrou-se segura. visto que não houveram complicaçòes no periodo pós-operatório que pudessem ser advindas de falhas do assepsia e anti-sepsia.

A percussão digital do abdômen demonstrou ser forma satisfatória para o controle de sua distensão. A pressão intraabdominal ao redor de $15 \mathrm{~mm} l \mathrm{lg}$, medida com manometro de mercúrio em um dos animais, proporcionou boa visualização dá cavidade sem incorrer em riscos. nào sendo observadas alterações cardiorrespiratórias em decorrência de compressão diafragnática. Pressão de $25 \mathrm{~mm} / \mathrm{g}$ incorre em exirema distensĩo da parede abdominal sem proporcionar bencficio adicional. () uso de ar ambiente para instauração do pneumoperitôn io foi prático e seguro. não acarretando complicações relacionadas com sua infusĩo na cavidade peritoneal. Sinais de desconforto abdominal não foram verificados no periodo pos-operatório.

A divisão do abdômen em três regiōes (cranial. central c caudal), feita através de linhas imaginárias, foi auxiliar na avaliação da disposição topográfica das estruturas anatômicas, estabelecendo sua abordagem mais apropriada, não havendo contudo distribuição estancuc, uma vez que o sistema digestivo do eqüino possui ampla mobilidade no interior da cavidade abdominal.

O uso da pinça de preensão féz-se necessário em algumas explorações com o intuito de lacilitar a identificação das estruturas. A tração de órgãos de pequeno diâmetro, como intestino delgado e cólon menor, foi isenta de riscos, nào sendo possivel sua utilização a nivel de cólon maior c órgãos parenquimatosos. Além do tracionamento, o deslocamento de estruturas com a superficic lateral da pinça é manobra de grande praticidade. tendo sido seu cumprimento considerado satisfatório nas manipulaçòes realizadas.

As estruturas comumente observadas durante os exames laparoscópicos foram: cupula diafragmática (porçào muscular). centro frênico (porção tendinea), lobos hepáticos, estomago. epíploon, baço (ápice c corpo), cólon maior (esquerdo. direito e flexuras), intestino delgado, ceco (base, corpo e ápice), cólon menor, útero, bexiga e ancis ingüinais.

Na regiào cranjal do abdômen pôde-se observar a porção muscular da cúpula diafragmática em $100 \%$ dos casos ( 17 animais). o centro frênico cm 88,2\% (15 animais), os lobos hepáticos cm $94.1 \%$ (16 animais) do lado direito e $82.4 \%$ ( 14 animais) do lado esquerdo (Fig. 3). O estomago foi visualizado em apenas 9 animais $(52.9 \%)$ e unicamente na região cranial esquerda do abdomen (Fig. $3)$, sendo que em 4 animais $(23.5 \%)$ estava parcialmente recoberto pelo epiploon. () intestino delgado póde ser melhor observado do lado esquerdo em 14 animais $(82,4 \%)$. () ápice do baço, localizado apenas do lado esquerdo, foi visto cm 9 animais $(52,9 \%)$ nesta região (fig. 3). As flexuras esternal e dialragmática. posicionadas transversalmente ao eixo longitudinal do abdomen, estavam presentes em 70.6\% dos casos. l:m apenas 3 animais $(17.6 \%)$ parte do corpo e ápice do eceo atingiram a região cranial do lado direito. 
Atraves da abordagem realizada na região central observaram-se apenas os intestinos e baço (Figs. 4 e 5 ). I:m todos os animais o intestino delgado foi visto principalmente do lado esquerdo do abdômen, bem como o baço e o cólon maior esquerdo. que puderam ser observados em lodos os animais c ocupando a maior parte deste lado. Já a flexura pélvica pôde ser visualizada em apenas 4 animais $(23,5 \%)$. O lado direito desta regiào é ocupado basicamente pelo cólon maior dircito e ceco, estando estes órgàos presentes respectivamente em $76,5 \%$ e $88.2 \%$ dos casos (Fig. 5 ). 0 cólon menor foi observado em apenas 7 animais $(41,2 \%)$ ocupando a regiào central esquerda (Fig. 4) e en 9 animais $(52,9 \%$ ) a região central direita. ( ) ligamento ceco-cólico (Fig. 5) foi identificado cm apenas 3 animais $(17,6 \%)$.

Devido ao pequeno diâmetro abdominal na região caudal, o pneumoperitônio é fundamental para permitir o afastamento de sua parede en relaçào às vísceras. No lado direito observou-se a base e o corpo do eceo cm 11 animais $(64,7 \%)$, porçós do intestino delgado em 7 animais (41.2\%), e principalmente o cólon menor (88.2\% dos casos). () lado esquerdo ć ocupado pelo cólon menor, visualizado $\mathrm{cm} 88.2 \%$ dos casos, além do intestino delgado $(76.5 \%)$ e flexura pélvica $(41.2 \%)$. $A$ bexiga e anéis ingüinais (Fig. 6) foram explorados com auxilio da pinça de precnsão na maioria dos exames, podendo ser identificaveis respectivamente em 9 $(52.9 \%)$ e 8 animais $(47.1 \%)$. () utero foi visualizado em apenas duas éguas devido à gestação.

\section{DISCUSSĀO}

Assim como descrito por Wilson ${ }^{25}$ (1983) e Fischer ef al. ${ }^{4}$ (1986). consideramos de fundamental importância o jejum alimentar prolongado para que se obtenha um esvaziamento parcial dos compartimentos intestinais, possibilitando uma melhor visualização das demais estruturas anatomicas.

Nào houve complicaçòes relacionadas com a técnica de anestesia geral inalatória por nós empregada, estando de acordo com os achados de Holland ef al. ${ }^{x}(1981$ ) e Anderson el al. (1993). Devemos tambem levar em consideração que certas areas são bem visualizadas apenas pela abordagem mediana ventral, com o animal posicionado em decubito dorsal. como já citado por Wildt ef al. ${ }^{21}(1977 b)$ e Fischer ef al.t (1986). c que nesse caso devemos preferercialmente lançar mão do uso de anestesia geral volatil quando a espécic em questão é eqüina.

Vários são os métodos de esterilização do equipamento. Megale ef al. ${ }^{15}(1956)$ e Silva: Megale ${ }^{19}(1971)$ utilizaram amônio quatemário. Soluçào de clorexidine í citada por Boyd: Ducker (1973) e Wildt et al.23 (1977a). Mais recentemente tem-se optado pelo uso de óxido de etileno (l ambert el al. ${ }^{12}, 1983$ ) ou soluçào de glutaraldeido (McDonald ${ }^{13}, 1982$ ). Optamos em nosso experimento pelo uso do glutaraldeido devido ao seu alto poder bactericida. baixo custo, praticidade e rapide\% do procedimento, diferenciando do método empregado por McDonald ${ }^{13}(1982)$ por utilizarmos um periodo superior de imersão e posterior lavagem do equipamento com solução lisiológica, evitando assim possivel irritação do peritonio, o que levou a bons resultados, visto que nào houve manifestação de dor ou outras complicaçòes no periodo pósoperatório.

() uso de pneumoperitônio, com o intuito de melhorar o campo visual durante o exame laparoscopico. descrito inicialmente por Kelling'1 (1901), tem sido empregado por virios autores (Phillippo el al. ${ }^{17}, 1971$; Wildt e' al. ${ }^{20}$. 1973; Wishart; Snowball26, 1973: Boyd: Ducker', 1973; Wildt e' al. ${ }^{23} .1977 a$; Wildt o' al.21.1977b; Holland", 1981: Fischer \&f al.t.1986; (jomef", 1993) de forma satisfatória, vindo em congruéncia aos nossos achados. que demonstram a amplitude de visualização dos órgãos com o uso dessa técnica. limbora diferentes gases tenlam sido utilizados para se obter o pneumoperitônio, como o dióxido de carbono (Phillippo el al. ${ }^{17}$. 1971: Fischer et al. $\left.{ }^{4}, 1986\right)$ e oxido nitroso (Wilson ${ }^{25}, 1983$ ), pudemos constatar que nossos resultados foram amplamente satisfatórios usando-se simplesmente ar ambiente. fato este ja observado por Kelling" (1901). Boyd: Ducker² (1973) e Holland ef al. ${ }^{8}$ (1981). A infusão de óxido nitroso para instalaçio do pncumoperitônio até atingir a pressào intra-abdominal de $40 \mathrm{mmH}$. previamente a introdução do trocarte. é citada por Wilson 25 (1983). Nós consideramos, com base em nossos resultados, que a pressão adequada está entre 15 e $20 \mathrm{~mm}$ lg. nào devendo ultrapassar 25 mmlig, o que levaria à distensão exacerbada da parede abdominal. além do risco de colapso cardiorrespiratório devicto a excessiva compressão diafragmática. limbora trabalhando com animais de pequeno porte, valor semelhante é citado por Jones ${ }^{10}$ (1990), que em seu trabalho não recomenda uso de pressĩo superior a 20 $\mathrm{mmlig}$.

$\Lambda$ introdução do trocarte previamente à insuflaçào da cavidade abdominal é citada por Fischer ef al. ${ }^{4}(1986)$. Lintretanto, assim como Wilson ${ }^{25}$ (1983), achamos mais prudentc a instalaçao do pneumoperitônio antes da introdução do trocarte, diminuindo desta forma riscos de perluração ou laceração de órgãos.

Com o posicionamento do paciente em decúbito dorsal, os órgàos abdominais deslocam-se dorsalmente. havendo afastamento destes em relação à parede abdominal, principalmente na regiào xifóide, o que facilita em muito a introduçào do trocarte neste local, independente da instalação ou não de pneumoperitónio. dai a escolha deste como sendo o primeiro ponto de acesso para a nossa exploração, procedimento não citado por outros autores.

A divisão do abdômen em regiões, método ja utilizado em càes por (jomez" (1993), visa correlacionar as diferentes estruturas anatômicas com sua localização, racionalizando o exame laparoscópico quando da escollha do acesso. () emprego desse método facilitou em muito a descrição da nossa exploração. c certamente propiciará uma orientação adequada para futuras abordagens laparoscópicas em eqüinos.

Assim como nos esludos de Boyd: Ducker2 (1973); (irauer ef al. 7(1983). Jones 100 (1990) e (iomez" (1993), o uso da pinça de prênsào foi de fundamental importancia para manipulação das estruturas abdominais, principalmente do intestino delgado e cólon menor, oferecendo boa segurança c firmeza no momento da traçĩo desses órgãos. O comprimento ideal da pinça de preensão para sua utilização em eqüinos não é referido pelos autores consultados, porém, a pinça com $50 \mathrm{~cm}$ de comprimento foi suticiente para a realização das exploraçòes.

Não há relatos ou estudos na literatura que descrevam a distribuição dos órgãos abdominais do cqüino por via laparoscópica com abordagem mediana ventral. o que nos impossibilita comparaçào objetiva com outros autores.

A cupula diafragmatica co ocentro frênico puderam ser bem 


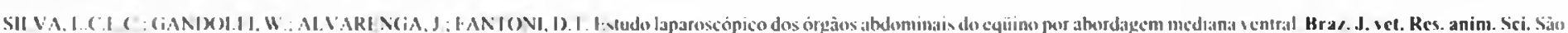
P'aule, v.34, a.4. p.211-217.1447

visualizados atraves do acesso retro-xifoide, abordando a região crantal do abdomen, o que não ocorre através do acesso pelo tlanco com o animal em posiçào quadrupedal como citado por Wil$\operatorname{son}^{25}(1983)$ e Fischer ef al. ${ }^{4}(1986)$. devido principalmente à distancia entre o ponto de penctração do trocarte e o diafragma. Neste casso. o acesso retro-xifóide pode estar indicado para a valiaçào de integridade do diafragma. lam apenas dois casos houve recobrimento do centro frênico pelo cólon maior. impossibilitando sua observaçao. $\wedge$ intima relaçào do diafragma com os órgàos da cavidade torácica pode vir a se tormar mais uma aplicação da récnica laparoscópica. Além de estomago. intestimo delgado e flexuras esternal e diafragmatica, os lobos hepáticos também podem ser amplamente visualizados pelo acesso retro-xiföide. sendo uma excelente abordagem para realização de biopsias deste orgào, a exemplo da técnical utilizada por Jones ${ }^{10}(1990)$. embora cmpregada em pequenos animais.

O accsso pre-umbilical promove ampla visão do baço, cólon maior. intestino delgado e ceco. Segundo fïischer ef alt (1986) estes orgãos tambem seriam observados pelos flancos dircito e esquerdo, porcim atraves de outro ângulo e nào com a mesma extensão, ficando a visualização restrita a apenas um segumento.

A bexiga, abordada pelo acesso retro-umbilical, identificada em apenas () animais (52.9\%) do nosso experimento, também pode ser explorada com abordagem pelo tlanco. bem como os órgàos reprodutivos internos da têmea, segundo as técnicas descritas por Wilson 25 (1983) a fischer el al. ${ }^{4}$ (1986). (Os ancis ingüinais internos nos machos puderam ser visualizados em $58.8 \%$ dos casos no lado direito e $47.1 \%$ no esquerdo, não havendo daclos na literatura que possam confrontar com nossos resultados.

()utros orgãos ou estruturas, como o duodeno, rim direito e espuerdo, ureterese ligamento nefro-explêniconào foram observados $\mathrm{cm}$ abordagem pela linha mediana ventral, pois cles localizam-se proximo a parede dorsal do abdomen, licando recobertos pelas visceras quando do decubito dorsal. Nestes casos está indicado o acesso pelo flanco com o animal em posiçào quadrupedal (Fischer (1 al. $\left.{ }^{+}, 1986\right)$ ou cm decíbito lateral, a exemplo do que está descrito para pequenos animais (Wilk ef al. ${ }^{21}$, 1977b; Jones'to, 190(); (iomce". 1993).

\section{CONCLUSÕES}

O presente estudo nos permite concluir que:

1. O periodo de jejum foi suliciente para lacilitar a exploração da cavidade abdominal.

2. A técnica anestésical empregada é segura para a realizaçào de exame laparoscipico.

3. O método de esterilização do equipamento pelo glutaraldeido foi satisfatorio.

4. A prática de pneumoperitônio foi fundamental para a boa isualização dos órgãos abdominais.

5. A pressio intra-abdominal entre 15 e $20 \mathrm{~mm} / \mathrm{lg}$ promoveu distensão abdominal suficiente e não levou a alteraçós cardiorrespiratorias significativats no paciente. sendo o controle através de percussio digital procedimento clásicico e eficiente.

6. () uso de ar ambiente para insullar a cavidade abdominal demonstrou ser método confiaivel.

7. $\Lambda$ division da cavidade abdominal do eqüino em três regiòes facilitou o estudo topográlico dos orgãos.

8. O uso da pinça de precnsão para manipulação dos órgàos abdominais do eqüino auxiliou o exame laparoscópico.

9. O acesso retro-xifóide permitiu a observação do diafragma. centro frenico, estomago, figado e flexuras esternal e diafragmatica. 10. () acesso pré-umbilical, abordando a regiào central. deve ser utilizado para inspecionar o intestino delgado, cólon maior, ceco e baço.

11. Através do acesso retro-umbilical teremos melhor visualização do colon menor, bexiga, base do eeco. Hexura pélvica. anel ingüinal e cordào espermático.

\section{SUMMARY}

This study describes the anatomotopographic position of horse abdominal viscera using laparoscopy. Three differents approaches were used: retroxiphoid, preumbilical and retroumbilical. Fifty one laparoscopic examinations were performed in 11 geldings and 6 males of differents breeds. and ages ranging from 18 months old to 24 years old. The animals were positioned in dorsal recumbency under general anesthesia. Pneumoperitonium was produced using air for a better visualization of the abdominal cavity. This procedure allowed the examination of the diaphragma, stomach, epiplon, liver, spleen, cecum, large colon, small colon, small intestine, urinary bladder, uterus and inguinal rings. This is a safe method to evaluate abdominal cavity and complement the usual procedures in horse diagnostic laparoscopy.

\section{UNITERMS: Laparoscopy; Endoscopy: Peritoneoscopy; Equidae}

\section{REFERENCIAS BIBIIOGRÁFICAS.}

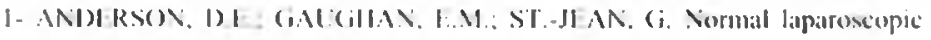

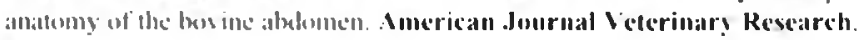
1.74. $0.7 . p .1170 .6 .1493$.

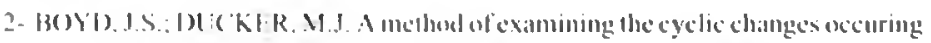

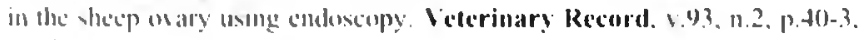
1973

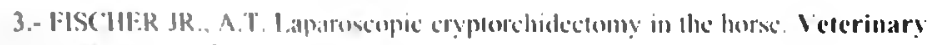

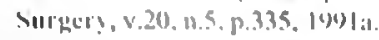

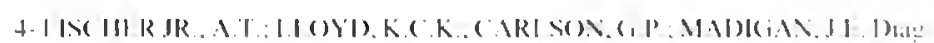
novac laparuscops m the huse Jumral ol the Imerican I eterioary Vledi-

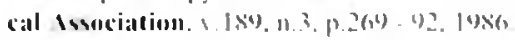

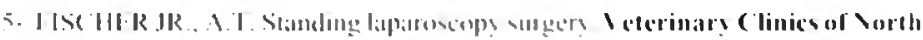

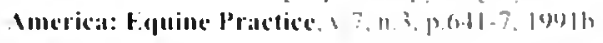

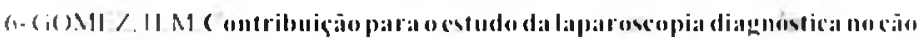

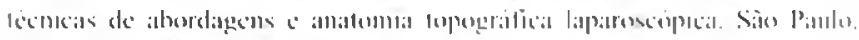

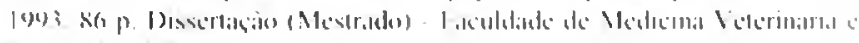

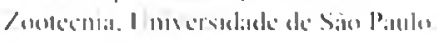




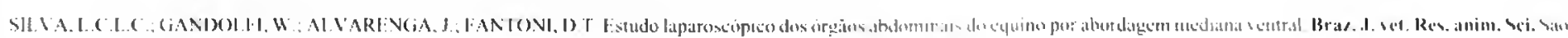
P:sulo, vi,3t, nt. P 211-21?, 199?

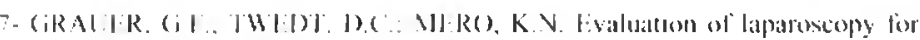
obtammy renal bopsy specimces lirum dogs and wals. Journal of the American Veterinary Medical Association, v. I8.3, 11.6. p.67.7-9. 198.?.

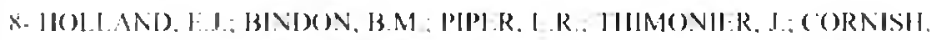

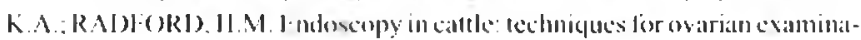
tion by the paralumbar and mid-icntral roules. Animal Reproduction Science.1.4. 11.2. p. 127-35. 1981

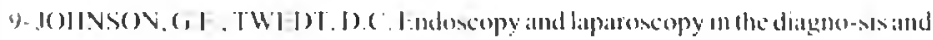

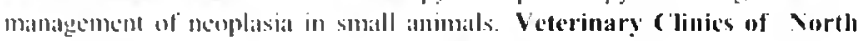
America. C linical Veterinary (Oncology: 1.7. 1. 1. p.77-92. 1977

| ()- JON]:S. IS I). L .aparoscopy. Veterinary Clinics of North Anerica. I eterinary Findoscopy, 1.20. 15.5. 124.3-63. 1990

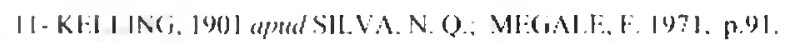

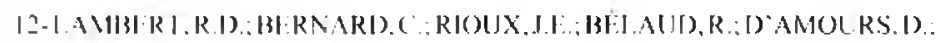
MoNTRE:LIL. A. Indoscopy in the ciltle by the paralumbar route: technique for ovarian examisation and follicular aspiration. Theriogenology 4.20 .11 .2$. p. 149.61. $19 \times 3$.

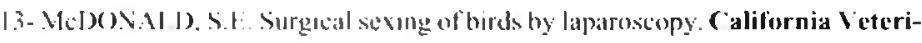

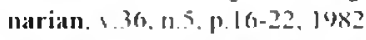

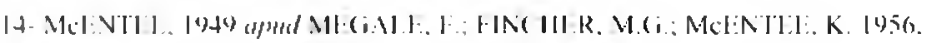
p. 109

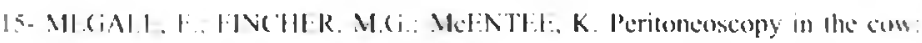

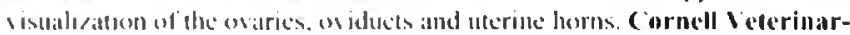
ian. 1.46. 11. I. p. 109-21, 1956.

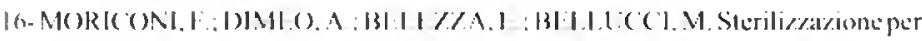

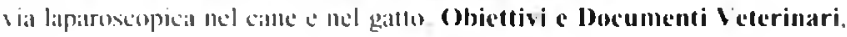
1. (1). 11. 3. p.13-6. 1484.

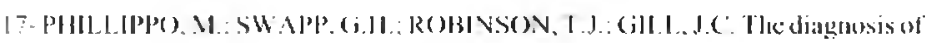
pregnancy and estimation ol fexelal numbers in sheep by laparoscupy Journal of Reproduction and Fertility. $1.27,11.1 .19 .129-32.1971$

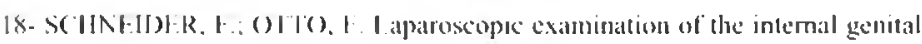
(rgans of cattle Schweizer Archiv fur Tierheilkunde. v. I I6, n. 2, p. I113 -9, 1974

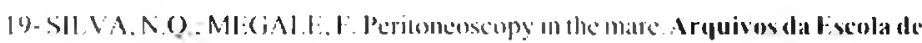
Veterinaria da Inisersidade Federal de Minas (ierais. 2.23, p.91-101. |4? 1 .

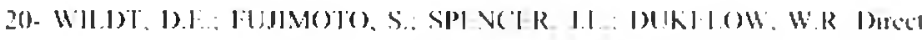

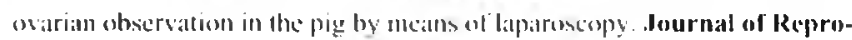

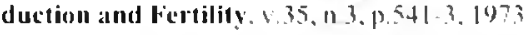

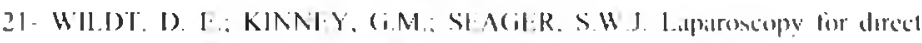
(hsersation of internal urgansolibe domestac call and dog Ineritan dournal Veterinary Rescarch, $5.38,119,01429,32,1977$ h

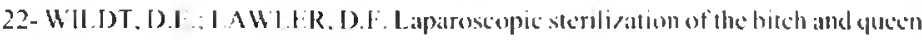
by uterine hom occlusion. American Jumrnal Velerinary Researeli, 1.46. 17.4. $1.8(14-9.1985$.

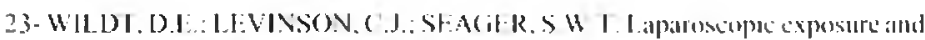
sequential observation of the onary of the cycling hitch. Inatomical Record. 1.184, 11.3. p.44.3-50. 1977a.

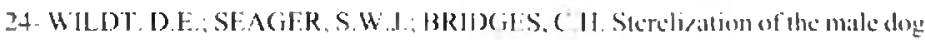
and cat by laparuscopic ocelusion of the ductus defirens. Ime rican Iournal Veterinary Research. $6.42, n, 11,0.1 \times 88-97.19 \times 1$.

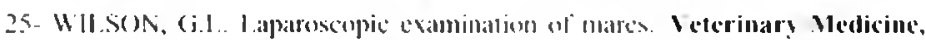

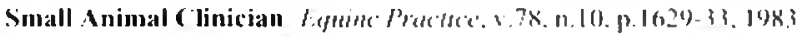

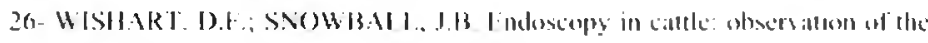
unary in situ. Veterinary Record. 6, 9?. n.6. p. 1,39-4.3. 1973

Recebido para publicação: 14/1 1/95 Aprovado para publicação: $08 / 08 / 97$ 